\title{
BMJ Open Weekly variations of stroke occurrence: an observational cohort study based on the Kyoto Stroke Registry, Japan
}

\author{
Kazuo Shigematsu, ${ }^{1}$ Yoshiyuki Watanabe, ${ }^{2}$ Hiromi Nakano, ${ }^{3}$ on behalf of the Kyoto \\ Stroke Registry Committee
}

To cite: Shigematsu K, Watanabe $\mathrm{Y}$, Nakano $\mathrm{H}$, et al. Weekly variations of stroke occurrence: an observational cohort study based on the Kyoto Stroke Registry, Japan. BMJ Open 2015;5:e006294. doi:10.1136/bmjopen-2014006294

- Prepublication history and additional material is available. To view please visit the journal (http://dx.doi.org/ 10.1136/bmjopen-2014006294).

Received 6 August 2014 Revised 8 February 2015 Accepted 10 February 2015

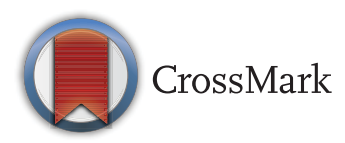

${ }^{1}$ Department of Neurology, National Hospital Organization, Minami Kyoto Hospital, Kyoto, Japan ${ }^{2}$ Department of Epidemiology for Community Health and Medicine, Kyoto Prefectural University of Medicine, Graduate School of Medical Science, Kyoto, Japan ${ }^{3}$ Department of

Neurosurgery, Kyoto Kidugawa Hospital, Kyoto, Japan

Correspondence to Dr Kazuo Shigematsu; neuron.k07@gmail.com

\section{ABSTRACT}

Objectives: Understanding the temporal pattern of stroke onset and exploring the possible triggers are important strategies to reducing the incidence of stroke. If stroke occurs frequently on a specific day of the week, it is assumed that other factors, that is, 'triggering factors', induce stroke. The aim of the study is to investigate differences in the incidences of stroke among days of the week.

Design: Hospital-based registry stroke over an 11-year period.

Setting: Kyoto Prefecture, Japan.

Participants: A total of 13788 patients with stroke identified from January 1999 to December 2009 inclusive in the entire Kyoto Prefecture and registered in the Kyoto Stroke Registry (KSR).

Main outcome measures: Patients with stroke were classified into seven groups based on the day of the week on which stroke developed. We confirmed the differences in the incidence among days using the $\chi^{2}$ test and then performed multinomial logistic analysis referring to the stroke incidence on Sunday to calculate the $\mathrm{OR}$ and $95 \% \mathrm{Cl}$ of the stroke occurrence on each day of the week.

Results: The OR $(95 \% \mathrm{Cl})$ for stroke occurring on Monday, Tuesday, Wednesday, Thursday, Friday and Saturday was 1.157 (1.030 to 1.293$), 1.101$ (0.981 to 1.236), 1.059 (0.943 to 1.188), 1.091 (0.972 to 1.225), 1.053 (0.938 to 1.205 ) and 1.074 (0.956 to 1.205), respectively. After stratification by stroke subtypes, cerebral infarction occurred more frequently on Monday than on Sunday (OR and $95 \% \mathrm{Cl}$ were 1.189 and 1.034 to $1.366, p=0.014$ ) independent of age and gender. There was no significant day of the week variation in cerebral haemorrhage or subarachnoid haemorrhage.

Conclusions: Some factors that arise periodically appear to affect the incidence of cerebral infarction, which gradually develops over years, and this suggests an aetiological mechanism different from the conventional cumulative effect of risk factors due to long-term exposure. We propose a hypothesis that there is a 'triggering factor' for the development of cerebral infarction.

\section{Strengths and limitations of this study}

- The study is based on a large stroke registry with 13788 patients with stroke over an 11-year period.

- Effects of a day of the week on stroke development should be different among societies, since lifestyles based on a day of the week are largely determined by the society. In a contemporary society where complex lifestyles prevail, the effects of a day of the week on stroke development should be less outstanding or may be concealed.

- We confirmed that the incidence of cerebral infarction was high on Monday independent of age and gender.

- The reasons for the weekly variation of stroke incidence remain unclear.

\section{INTRODUCTION}

Stroke is regarded as a lifestyle-related disease based on the chronic deterioration of cerebral arteries in principle. ${ }^{1}$ Long-lasting exposure to risk factors, such as hypertension, hyperlipidaemia, diabetes mellitus, smoking and so on, should give rise to damage of cerebral arteries, such as atherosclerosis, ${ }^{2}$ which should lead to the obstruction of cerebral blood flow at the final stage. ${ }^{3}$ Therefore, longterm, yearly-based effort to reduce risk factors should be important to prevent stroke. ${ }^{45}$ On the other hand, transient hypertension such as white coat hypertension without sustained hypertension, for example, is not regarded as a conventional risk factor of stroke. ${ }^{6} \quad 7$ However, some studies reported that stroke occurs more frequently on Mondays, ${ }^{8-11}$ and so does myocardial infarction. ${ }^{12}$ Although causes of weekly variation of a lifestyle-related disease, such as cerebral infarction (CeI) and myocardial infarction, remain unclear, it is of great importance to verify the variation and 
search factors that possibly affect the variation. If CeI occurs on a basis of atherosclerosis as a result of yearly accumulation of risk factors, it should be unlikely that its incidence differs among days of the week because the day of the week on which the total of risk factors reaches a level may be random. Therefore, if stroke, which is the final step of atherosclerosis, occurs more frequently on a specific day of the week, it is assumed that other factors, in addition to atherosclerosis caused by cumulative risk factors, that is, 'triggering factors', induced stroke. ${ }^{13}$ Similarly, if the incidence is low on a specific day of the week, there may be 'delaying factors'. Understanding the temporal pattern of stroke onset and exploring the possible triggers are important strategies to reduce the incidence of stroke. In Kyoto, there is an ongoing stroke registry which covers the entire prefecture. We identified the day of the week on which stroke developed in these data, and examined the presence or absence of differences in the incidence, patients' history, and prognosis among days of the week employing multivariate analysis. In this study, we investigated differences in the incidences of the three major subtypes of stroke: CeI, cerebral haemorrhage $(\mathrm{CH})$ and subarachnoid haemorrhage (SAH), among days of the week.

\section{METHODS}

We analysed all new patients with stroke identified from January 1999 to December 2009 inclusive in the entire Kyoto Prefecture and registered in the Kyoto Stroke Registry (KSR). The details of the KSR have been previously reported. ${ }^{14-18}$ Briefly, patients with stroke were registered in the KSR in cooperation with all medical institutions belonging to the Kyoto Medical Association to investigate the actual state of patients with stroke in the Kyoto Prefecture, and the data are analysed aiming at promotion of countermeasures against stroke from prevention to rehabilitation to improving impairment as much as possible to avoid staying in hospitals and facilities and returning home. The Kyoto Medical Association distributes the registration form to all cooperative facilities, and physicians in charge at cooperative facilities fill the form and send it back to the Medical Association. The data were summed by the Medical Association. The registration items included age, gender, date and time of onset, time of consultation, medical histories (hypertension, arrhythmia, diabetes mellitus and hyperlipidaemia), blood pressure on consultation, presence or absence of arrhythmia and history of examinations (CT, MRI). Stroke was classified into three major subtypes (CeI, CH and $\mathrm{SAH}$ ) according to the WHO definition. ${ }^{19}$

This research was performed in accordance with the ethical principles for medical research involving human participants outlined in the Declaration of Helsinki. Since all identifying personal information was stripped from the secondary files before analysis, the boards waived the requirement for written informed consent from the patients involved.
All patients with stroke were divided into seven groups (Sunday-Saturday) based on the day of the week on which stroke developed. Since data were collected over 11 years starting on Friday and ended on Thursday, the total number of days was 574 for each day of the week. For a between-group comparison of patients' history, the basic statistics or frequency was calculated. On the assumption that stroke development is independent from days of the week, the expected value is $1 / 7$ for each day of the week. First, differences in the incidence were analysed among days of the week for the entire period using the $\chi^{2}$ test, and a significant difference was detected. Second, multinomial logistic analysis was performed referring to the incidence at the start of the week (Sunday), and the OR and 95\% CI of the stroke occurrence on each day of the week compared to that on Sunday were calculated, in which no multiplicity adjustment was applied because a significant difference was detected in the above $\chi^{2}$ test and to reduce the error of the second kind (reduce the risk of overlooking differences). Using multinomial logistic regression, stroke case across the week was modelled as a dependent variable. From such models, three regression coefficients were estimated, which provide estimates of the OR of stroke occurring on Monday, Tuesday, Wednesday, Thursday, Friday and Saturday versus Sunday as a reference. The OR was calculated as $\mathrm{e}^{\beta}$ with $95 \% \mathrm{CI}=\mathrm{e}^{(\beta \pm 1.96 \times \mathrm{SE})}$. Here, ' $\beta$ ' is the regression coefficient corresponding to Monday, Tuesday, Wednesday, Thursday, Friday or Saturday (with Sunday as a reference), and 'SE' is the SE of ' $\beta$ '. ${ }^{11}{ }^{20}$ The subjects were divided into two groups with an onset age of 64 years or younger and 65 years or older, and multinomial logistic analysis with adjustment for this age category and gender was performed referring to the incidence with Sunday as a reference, as described above. Third, the presence or absence of a medical history of hypertension was added to the adjustment factors, and multinomial logistic analysis was similarly performed. We chose hypertension history as an adjustment factor, which is the major risk factor of stroke and was the most prevalent in the study cohort. As described above, on the assumption that there is no difference in the incidence among days of the week, the expected value is $1 / 7$ for each day. The presence of a significant difference of patients' history was also investigated between patients who developed stroke on Sunday or Monday and patients who developed stroke on the other days, as well as among patients who developed stroke on each day. The $\chi^{2}$ test and Student $t$ test were used for categorical and numerical data, respectively. Statistical analyses were performed using SPSS for windows, V.19.0 (IBM). All reported $\mathrm{p}$ values were two-sided. Statistical significance was set at $\mathrm{p}<0.05$.

\section{RESULTS}

We reviewed 14268 patients with stroke newly identified in the Kyoto Prefecture from January 1999 to December 
2009. Of these, 12774 (89.5\%) underwent a CT, 9232 $(64.7 \%)$ an MRI scan, $2504(17.5 \%)$ an angiography and $342(2.4 \%)$ a scintigraphy for blood flow. The number of patients who neither had CT nor MRI was $121(0.9 \%)$. Excluding $480(3.3 \%)$ unclassified patients, the study cohort had 13788 patients divided into 9011 (65.4\%) CeI, 3549 (25.7\%) $\mathrm{CH}$ and $1197(8.7 \%) \mathrm{SAH}$ cases. A small number of patients had a combination of stroke types as follows: 12 with $\mathrm{CeI}$ and $\mathrm{CH}, 4$ with CeI and $\mathrm{SAH}$ and 15 with $\mathrm{CH}$ and $\mathrm{SAH}$.

Patients' history is shown in table 1. Patients' history in each stroke subtype is summarised in online supplementary tables S1-S3. The significance ( $p$ value) of the difference of each variable among patients who developed stroke on each day is summarised in online supplementary table $\mathrm{S} 4$.

The incidence of stroke by day of the week decreased in the order of Monday, Tuesday, Thursday=Friday, Wednesday, Saturday and Sunday. The results of multinomial logistic analysis are shown in table 2 . The crude OR and $95 \%$ CI of CeI (vs that on Sunday) were significantly high on Monday (1.182, 1.095 to 1.276 , $\mathrm{p}<0.001)$ and remained significant even after adjustment for age group, gender and hypertension history. On the $\chi^{2}$ test of the difference between the actual incidence on each day of the week and the expected value $(1 / 7$, about $14.3 \%)$ on the assumption of the absence of a difference among days of the week, the $\mathrm{p}$ values were, in the order from Sunday, $0.180,<0.001$, $0.874,0.214,0.770,0.826$ and 0.562 , respectively. On the $\chi^{2}$ test between the combined value of Sunday and Monday and the expected value, 2/7, was 0.139 . The incidence of $\mathrm{CH}$ was high on Tuesday (OR and $95 \%$ CI were 1.162 and 1.027 to $1.315, \mathrm{p}=0.016$ ), but the difference after adjustment with the age and gender was not statistically significant. The incidence of SAH was not significantly different among days of the week.

\section{DISCUSSION}

Acute cerebrovascular events, including not only stroke but also transient ischaemic attack, are not randomly distributed over time but show specific temporal patterns of occurrence. ${ }^{21} 22$ The incidence of stroke varied among days of the week and it was high on Mondays, confirming the results of previous reports. ${ }^{8-11} 2324 \mathrm{~A}$ high incidence of myocardial infarction on Monday, which is caused by the interruption of arterial blood flow in a manner similar to CeI, has also been reported. ${ }^{12} 2526$ In our study, the weekly variation of the incidence was statistically significant for all stroke and for cerebral infarction. No significant weekly variation was noted in the incidence of haemorrhagic stroke, that is, $\mathrm{CH}$ and $\mathrm{SAH}$. We calculated that the OR of development on Monday compared to that on Sunday was estimated after adjustment for age, gender and hypertension history and found that the weekly variation of the incidence of CeI was independent from the age, gender and hypertension history.

It is difficult to identify the cause of this weekly variation. Date is socially determined and is not directly associated with a disease. Monday preference has been reported by several authors for acute cardiovascular diseases, not only myocardial infarction ${ }^{12} 2^{25}{ }^{26}$ but also acute aortic dissection and rupture, ${ }^{27}$ sudden deaths and cardiac arrests. ${ }^{28}{ }^{29}$ Sunday is a holiday and Monday is the day of starting work in general. There is an expression: Monday blues. Blood pressure elevation by stress may be the cause. The weekly variability seems to be independent of the presence of common risk factors (age, gender, arterial hypertension, type 2 diabetes mellitus and dyslipidemia). ${ }^{27} 30$ The Monday preference of CeI might be explained by different risk factors such as biochemical factors associated with cardiovascular risk that can be less favourable on this day. ${ }^{31-33}$ No significant differences were noted in the medical history of hypertension or blood pressure on consultation on

Table 1 Summary of basic information of patients with stroke by day of the week $(n=13788)$

\begin{tabular}{|c|c|c|c|c|}
\hline \multicolumn{2}{|l|}{ Characteristic } & Sunday $(n=1863)$ & Monday $(\mathrm{n}=2151)$ & Tuesday $(n=1986)$ \\
\hline \multicolumn{2}{|l|}{ Age (mean $\pm S D)$} & $71.1 \pm 12.9$ & $71.3 \pm 12.6$ & $71.2 \pm 13.3$ \\
\hline \multicolumn{2}{|l|}{ Gender (man \% (n)) } & $54.9(1022)$ & $54.8(1179)$ & $55.1(1095)$ \\
\hline \multicolumn{2}{|c|}{ Systolic blood pressure (mean $\pm S D)$} & $161.3 \pm 30.9$ & $161.4 \pm 32.4$ & $161.3 \pm 31.7$ \\
\hline \multicolumn{2}{|c|}{ Diastolic blood pressure (mean $\pm S D)$} & $87.4 \pm 18.9$ & $87.7 \pm 19.0$ & $87.7 \pm 19.5$ \\
\hline \multicolumn{2}{|c|}{ Hypertension history, $(\%$, with/without/missing $(n))$} & $57.1 / 35.4 / 7.6$ & $57.0 / 35.5 / 7.5$ & $59.2 / 33.5 / 7.3$ \\
\hline Characteristic & Wednesday $(n=1943)$ & Thursday $(n=1962)$ & Friday $(n=1963)$ & Saturday $(n=1920)$ \\
\hline Age & $71.1 \pm 12.7$ & $71.4 \pm 12.4$ & $71.5 \pm 12.9$ & $71.1 \pm 13.2$ \\
\hline Gender & $54.3 / 45.7(1055 / 888)$ & $54.6 / 45.4(1071 / 891)$ & $56.1 / 43.9(1101 / 862)$ & $53.8 / 46.3(1032 / 888)$ \\
\hline Systolic blood pressure & $161.8 \pm 32.0$ & $161.3 \pm 31.2$ & $161.3 \pm 30.5$ & $160.6 \pm 31.7$ \\
\hline Diastolic blood pressure & $88.0 \pm 19.0$ & $87.7 \pm 18.7$ & $87.7 \pm 18.2$ & $87.6 \pm 18.9$ \\
\hline Hypertension history & $\begin{array}{l}56.6 / 35.7 / 7.8 \\
(1099 / 693 / 151)\end{array}$ & $\begin{array}{l}59.0 / 34.9 / 6.1 \\
(1157 / 685 / 120)\end{array}$ & $58.8 / 34.0 / 7.2$ & $58.9 / 33.6 / 7.5$ \\
\hline
\end{tabular}


Table 2 ORs and $95 \%$ Cls for the occurrence of stroke

\begin{tabular}{|c|c|c|c|c|}
\hline & \multirow[b]{2}{*}{ OR } & \multicolumn{2}{|l|}{$95 \% \mathrm{Cl}$} & \multirow[b]{2}{*}{ p Value } \\
\hline & & Lower & Upper & \\
\hline \multicolumn{5}{|l|}{ Stroke } \\
\hline Sunday & \multicolumn{3}{|c|}{ Reference } & \\
\hline Monday & 1.154 & 1.030 & 1.293 & 0.013 \\
\hline Tuesday & 1.101 & 0.981 & 1.236 & 0.100 \\
\hline Wednesday & 1.059 & 0.943 & 1.188 & 0.339 \\
\hline Thursday & 1.091 & 0.972 & 1.225 & 0.139 \\
\hline Friday & 1.053 & 0.938 & 1.183 & 0.379 \\
\hline Saturday & 1.074 & 0.956 & 1.205 & 0.228 \\
\hline \multicolumn{5}{|c|}{ Cerebral infarction } \\
\hline Sunday & \multicolumn{3}{|c|}{ Reference } & \\
\hline Monday & 1.189 & 1.034 & 1.366 & 0.014 \\
\hline Tuesday & 1.069 & 0.929 & 1.231 & 0.358 \\
\hline Wednesday & 1.011 & 0.876 & 1.167 & 0.877 \\
\hline Thursday & 1.082 & 0.940 & 1.246 & 0.276 \\
\hline Friday & 1.060 & 0.918 & 1.223 & 0.426 \\
\hline Saturday & 1.087 & 0.944 & 1.251 & 0.250 \\
\hline \multicolumn{5}{|c|}{ Cerebral haemorrhage } \\
\hline Sunday & \multicolumn{3}{|c|}{ Reference } & \\
\hline Monday & 1.044 & 0.830 & 1.313 & 0.713 \\
\hline Tuesday & 1.170 & 0.934 & 1.466 & 0.171 \\
\hline Wednesday & 1.165 & 0.928 & 1.463 & 0.188 \\
\hline Thursday & 1.088 & 0.865 & 1.368 & 0.471 \\
\hline Friday & 0.955 & 0.755 & 1.208 & 0.700 \\
\hline Saturday & 1.013 & 0.802 & 1.279 & 0.914 \\
\hline \multicolumn{5}{|c|}{ Subarachnoid haemorrhage } \\
\hline Sunday & \multicolumn{3}{|c|}{ Reference } & \\
\hline Monday & 1.201 & 0.779 & 1.852 & 0.408 \\
\hline Tuesday & 1.157 & 0.740 & 1.809 & 0.523 \\
\hline Wednesday & 1.195 & 0.773 & 1.846 & 0.423 \\
\hline Thursday & 1.413 & 0.922 & 2.167 & 0.112 \\
\hline Friday & 1.428 & 0.939 & 2.172 & 0.097 \\
\hline Saturday & 1.165 & 0.753 & 1.804 & 0.493 \\
\hline
\end{tabular}

between-group comparison. Assuming that there is no difference in incidence among days of the week, the expected value is $1 / 7$ for each day. The incidence on Sunday was significantly low, suggesting that rest delays the development of stroke. There was no significant difference between the rate of combined patients who developed stroke on Sunday and Monday and 2/7, suggesting that stroke which might have occurred on Sunday was 'delayed' and occurred on Monday. If there is a factor delaying the development, it may lead to stroke prevention. Further investigation is expected.

We would like to think about the risk factors. The day of the week is not a risk factor as defined in health parameters. The epidemiological definition of risk factors states that a factor is an attributable characteristic or exposure of an individual that increases the likelihood of a disease. Besides, can risk factors explain the phenomenon that the incidence is significantly high on some day and low on another day of the week? A factor influencing the development is called as a risk factor. However, 'days of the week' are markedly different from risk factors, such as hypertension ${ }^{34}$ and obesity. ${ }^{35}$ Conventional risk factors increase the risk of diseases, especially lifestyle-related diseases, ${ }^{36}$ through long-term exposure, but days of the week act through only 1 day exposure. The mean, median and most frequent age of the CeI patients analysed in this study were $73.3,74$ and 75 years, respectively. Assuming that stroke occurred at the age of 70 years, it developed at $70 \times 365$ days $=25550$ days without consideration of the leap years, and patients were exposed to each day of the week for 3650 days. Since the maximum difference in the frequency of exposure to each day among days of the week is 1 day, the numbers of Mondays in patients who developed stroke on Sunday and Monday were 3650 vs 3649 days, respectively, and the difference can be practically negligible. We might call Monday a risk factor. If so, however, everyone has virtually the same amount of the 'risk factor'. In contrast, the OR of Monday stroke development compared to that of Sunday was 1.18 (1.03 to $1.37, \mathrm{p}=0.014$ ), which could not be explained with the number of exposure days. Therefore, days of the week act in a way different from that of conventional risk factors, such as hypertension and obesity. Conventional risk factors act through long-term or repeated exposure, whereas this triggering or delaying factor acts through a very short exposure. For example, 'hypertension' acts through years of exposure in general. If Monday has a risk factor like 'hypertension', the patients who developed stroke on Monday were exposed for 3650 Mondays and those who developed stroke on the other day were exposed for 3649 Mondays. It is unlikely that the incidence differs between groups exposed for 3650 and 3649 days. Therefore, we termed factors inducing and delaving stroke 'triggering and delaving factors', distinguished from the term 'risk factors'. ${ }^{37}$ Our study and several other studies showed a high incidence of CeI on Mondays, suggesting that Monday contains a 'triggering factor'. Considering that the incidence was low on Sundays, Sunday may contain a 'delaying factor'. Less stress, less anxiety, sufficient time to sleep and rest may be a candidate for delaying factors. ${ }^{38}{ }^{39}$ Triggering and delaying are a matter of relativity. It cannot be clarified in this study whether both factors are present or only one of these is present. For example, the latter condition can be interpreted to mean that Monday contains many triggering factors while Sunday contains fewer triggering factors, reducing the incidence. Since days of the week are socially defined, it is unclear what biological factor serves as a triggering ${ }^{40}$ or delaying factor. Stress and rest are considered as candidates. ${ }^{39} 41-43$

The representative causes of $\mathrm{CeI}$ are considered to gradually aggravate over years in general. The accumulation of conventional risk factors results in the disease. In contrast, factors of 'days of the week' may not act through accumulation, as discussed above, and, at least, it may not directly act on atherosclerosis, for example. Dehydration, ${ }^{44}$ elevated blood coagulation ${ }^{45}$ and vasospasm $^{46}$ are considered as changes which influence the 
development of CeI and occur within a short time. We propose a hypothesis that some factor related to Monday induces these changes, and that the changes trigger CeI. Further studies are necessary to verify this hypothesis, but we expect that it promotes studies, gives tips to consider the developmental mechanism of CeI and leads to the prevention of CeI.

\section{LIMITATIONS}

The study has all the limitations that a retrospective cohort study may have. It was a retrospective analysis of data coming from a local registry; data obtained from registries might be biased towards under-reporting, because the report of stroke cases was left to physicians who had to fill a prespecified form and send it back to the Kyoto Medical Association; moreover, this modality of data collection may have introduced a selection bias, lack of logistical data.

It would have been interesting to evaluate the differences between each day of the week such as: stroke severity measured by the National Institutes of Health Stroke Scale (NIHSS), thrombolytic treatment, ischaemic stroke subtype. However, those data are not available in the KSR at the period of the study.

Risk factors for ischaemic stroke may be different from risk factors for haemorrhagic strokes. Exposure to some risk factors may be different by day. Lifestyles such as sleeping and drinking habits may change by the day. The causes of weekly variation of stroke occurrence remain unclear.

Although statistically significant, weekly variation was revealed only in ischaemic events; presumably, meaningful weekly variation was noticed in haemorrhagic stroke; Tuesday 1.170 (0.934 to 1.466$) \mathrm{p}=0.171$; Wednesday 1.165 (0.928 to 1.463$) \mathrm{p}=0.188$ in $\mathrm{CH}$, and Thursday 1.413 (0.922 to 2.167) $\mathrm{p}=0.112$; Friday 1.428 (0.939 to 2.172), $\mathrm{p}=0.097$ in SAH. The failure of the variation to reach statistically significant levels in $\mathrm{CH}$ and in SAH might be due to the lack of statistical power. This study could not explain the different pattern among stroke subtypes. However, the results suggest that there are different mechanisms of triggering events among stroke subtypes.

Another limitation of this study was the lack of logistical data.

Acknowledgements The authors would like to acknowledge the contribution of participating institutions and members of their staff who provided data in the development of the Kyoto Stroke Registry.

Funding This research received no specific grant from any funding agency in the public, commercial or not-for-profit sectors.

\section{Competing interests None.}

Ethics approval This research was approved by the Board of Directors, the Kyoto Medical Association, the Department of Health and Welfare, Kyoto Prefecture and the Ethics Committee of the National Hospital Organization, Minami Kyoto Hospital.

Provenance and peer review Not commissioned; externally peer reviewed.

Data sharing statement The data we used for the study are data of the Kyoto Stroke Registry. People can access it by obtaining permission from the committee (the Kyoto Stroke Registry Committee). The summary of the data (an annual report) is published every year and distributed to all hospitals belonging to the Kyoto Medical Association. The row data are not open to the public without specific reasons and permission.

Open Access This is an Open Access article distributed in accordance with the Creative Commons Attribution Non Commercial (CC BY-NC 4.0) license, which permits others to distribute, remix, adapt, build upon this work noncommercially, and license their derivative works on different terms, provided the original work is properly cited and the use is non-commercial. See: http:// creativecommons.org/licenses/by-nc/4.0/

\section{REFERENCES}

1. Shinton R. Lifelong exposures and the potential for stroke prevention: the contribution of cigarette smoking, exercise, and body fat. J Epidemiol Community Health 1997;51:138-43.

2. Chambless LE, Heiss $G$, Shahar E, et al. Prediction of ischemic stroke risk in the Atherosclerosis Risk in Communities Study. Am J Epidemiol 2004;160:259-69.

3. Kannel WB. Current status of the epidemiology of brain infarction associated with occlusive arterial disease. Stroke 1971;2:295-318.

4. Strong K, Mathers C, Bonita R. Preventing stroke: saving lives around the world. Lancet Neurol 2007;6:182-7.

5. Sacco RL. Risk factors, outcomes, and stroke subtypes for ischemic stroke. Neurology 1997;49(5 Suppl 4):S39-44.

6. Verdecchia P, Reboldi GP, Angeli F, et al. Short- and long-term incidence of stroke in white-coat hypertension. Hypertension 2005;45:203-8.

7. Khattar RS, Senior R, Lahiri A. Cardiovascular outcome in white-coat versus sustained mild hypertension: a 10-year follow-up study. Circulation 1998;98:1892-7.

8. Pasqualetti P, Natali G, Casale R, et al. Epidemiological chronorisk of stroke. Acta Neurol Scand 1990;81:71-4.

9. Kelly-Hayes M, Wolf PA, Kase CS, et al. Temporal patterns of stroke onset. The Framingham Study. Stroke 1995;26:1343-7.

10. Jakovljevic D. Day of the week and ischemic stroke: is it Monday high or Sunday low? Stroke 2004;35:2089-93.

11. Turin TC, Kita $Y$, Murakami $Y$, et al. Increase of stroke incidence after weekend regardless of traditional risk factors: Takashima Stroke Registry, Japan; 1988-2003. Cerebrovasc Dis 2007;24:328-37.

12. Willich $\mathrm{SN}$, Lowel $\mathrm{H}$, Lewis $\mathrm{M}$, et al. Weekly variation of acute myocardial infarction. Increased Monday risk in the working population. Circulation 1994;90:87-93.

13. Grau AJ, Buggle F, Heindl $S$, et al. Recent infection as a risk factor for cerebrovascular ischemia. Stroke 1995;26:373-9.

14. Shigematsu $\mathrm{K}$, Nakano $\mathrm{H}$, Watanabe $\mathrm{Y}$. The eye response test alone is sufficient to predict stroke outcome-reintroduction of Japan Coma Scale: a cohort study. BMJ Open 2013;3:e002736. doi:10.1136/bmjopen-2013-002736

15. Shigematsu $\mathrm{K}$, Nakano $\mathrm{H}$, Watanabe $\mathrm{Y}$, et al. Characteristics, risk factors and mortality of stroke patients in Kyoto, Japan. BMJ Open 2013;3:e002181. doi:10.1136/bmjopen-2012-002181

16. Shigematsu $\mathrm{K}$, Shimamura $\mathrm{O}$, Nakano $\mathrm{H}$, et al. Vomiting should be a prompt predictor of stroke outcome. Emerg Med J 2013;30:728-31.

17. Shigematsu $\mathrm{K}$, Watanabe $\mathrm{Y}$, Nakano $\mathrm{H}$, et al. Lower hazard ratio for death in women with cerebral hemorrhage. Acta Neurol Scand 2015 Published Online First: 3 Feb 2015. doi:10.1111/ane.12359. http://onlinelibrary.wiley.com/doi/10.1111/ane.12359/full

18. Shigematsu $\mathrm{K}$, Nakano $\mathrm{H}$, Watanabe $\mathrm{Y}$, et al. Speech disturbance at stroke onset is correlated with stroke early mortality. BMC Neurol 2013;13:87.

19. Hatano $\mathrm{S}$. Experience from a multicentre stroke register: a preliminary report. Bull World Health Organ 1976;54:541-53.

20. Turin TC, Kita Y, Murakami Y, et al. Higher stroke incidence in the spring season regardless of conventional risk factors: Takashima Stroke Registry, Japan, 1988-2001. Stroke 2008;39:745-52.

21. Manfredini R, Manfredini F, Boari B, et al. Temporal patterns of hospital admissions for transient ischemic attack: a retrospective population-based study in the Emilia-Romagna region of Italy. Clin Appl Thromb Hemost 2010;16:153-60.

22. Manfredini R, Manfredini F, Malagoni AM, et al. Day-of-week distribution of fatal and nonfatal ischemic stroke in elderly subjects. J Am Geriatr Soc 2009;57:1511-13.

23. Wang $H$, Sekine $M$, Chen $X$, et al. A study of weekly and seasonal variation of stroke onset. Int J Biometeorol 2002;47:13-20.

24. Manfredini R, Manfredini F, Boari B, et al. The Monday peak in the onset of ischemic stroke is independent of major risk factors. $A m ~ J$ Emerg Med 2009;27:244-6. 
25. Gnecchi-Ruscone T, Piccaluga E, Guzzetti S, et al. Morning and Monday: critical periods for the onset of acute myocardial infarction. The GISSI 2 Study experience. Eur Heart J 1994;15:882-7.

26. Spielberg C, Falkenhahn D, Willich SN, et al. Circadian, day-of-week, and seasonal variability in myocardial infarction: comparison between working and retired patients. Am Heart $J$ 1996;132:579-85.

27. Manfredini R, Manfredini F, Boari B, et al. Seasonal and weekly patterns of hospital admissions for nonfatal and fatal myocardial infarction. Am J Emerg Med 2009;27:1097-103.

28. Arntz HR, Willich SN, Schreiber C, et al. Diurnal, weekly and seasonal variation of sudden death. Population-based analysis of 24,061 consecutive cases. Eur Heart J 2000;21:315-20.

29. Peckova M, Fahrenbruch CE, Cobb LA, et al. Weekly and seasonal variation in the incidence of cardiac arrests. Am Heart $J$ 1999;137:512-15.

30. Manfredini R, Fabbian F, Pala M, et al. Seasonal and weekly patterns of occurrence of acute cardiovascular diseases: does a gender difference exist? J Womens Health (Larchmt) 2011:20:1663-8.

31. Karlinski M, Bembenek J, Grabska K, et al. Routine serum C-reactive protein and stroke outcome after intravenous thrombolysis. Acta Neurol Scand 2014;130:305-11.

32. Zhang JL, Yin $\mathrm{CH}$, Zhang $\mathrm{Y}$, et al. Plasma copeptin and long-term outcomes in acute ischemic stroke. Acta Neurol Scand 2013;128:372-80.

33. Blomstrand $\mathrm{A}$, Blomstrand $\mathrm{C}$, Ariai $\mathrm{N}$, et al. Stroke incidence and association with risk factors in women: a 32-year follow-up of the Prospective Population Study of Women in Gothenburg. BMJ Open 2014:4:e005173.

34. Gjerde G, Naess $\mathrm{H}$. Risk factor burden predicts long-term mortality after cerebral infarction. Acta Neurol Scand 2014;129:173-7.
35. Putaala J, Strbian D, Mustanoja S, et al. Functional outcome in young adult ischemic stroke: impact of lipoproteins. Acta Neurol Scand 2013;127:61-9.

36. Tveiten A, Ljostad U, Mygland A, et al. Functioning of long-term survivors of first-ever intracerebral hemorrhage. Acta Neurol Scand 2014;129:269-75.

37. Rantakomi SH, Laukkanen JA, Sivenius J, et al. Hangover and the risk of stroke in middle-aged men. Acta Neurol Scand 2013;127:186-91.

38. Jood K, Redfors P, Rosengren A, et al. Self-perceived psychological stress and ischemic stroke: a case-control study. BMC Med 2009;7:53.

39. Ernst E, Weihmayr T, Schmid M, et al. Cardiovascular risk factors and hemorheology. Physical fitness, stress and obesity. Atherosclerosis 1986;59:263-9.

40. Lantz M, Kostulas K, Sjostrand C. Migraine-related ischemic stroke? Acta Neurol Scand 2013;127:e18-23.

41. Kurl S, Laukkanen JA, Rauramaa R, et al. Systolic blood pressure response to exercise stress test and risk of stroke. Stroke 2001;32:2036-41.

42. Harmsen $P$, Rosengren A, Tsipogianni A, et al. Risk factors for stroke in middle-aged men in Goteborg, Sweden. Stroke 1990;21:223-9.

43. Harmsen $P$, Lappas $G$, Rosengren A, et al. Long-term risk factors for stroke: twenty-eight years of follow-up of 7457 middle-aged men in Goteborg, Sweden. Stroke 2006;37:1663-7.

44. Dahl MH, Ronning OM, Thommessen B. Delirium in acute strokeprevalence and risk factors. Acta Neurol Scand Supp/ 2010;122 (Suppl s190):39-43.

45. Back C, Thiesen KL, Skovgaard K, et al. RAAS and stress markers in acute ischemic stroke: preliminary findings. Acta Neurol Scand 2015;131:132-9.

46. Mishina M, Kim K, Kominami S, et al. Impact of polyunsaturated fatty acid consumption prior to ischemic stroke. Acta Neurol Scand 2013;127:181-5. 